\title{
Discussões sobre a representação da mulher no cinema de animação: Mulan e o conceito de polissemia feminina. \\ Lucas Sereda ${ }^{1}$
}

Em seu livro A Cultura da Mídia², Douglas Kellner tenta entender qual a relação entre o contexto e as novas produções culturais pós-anos 80 . O autor define o que é, para ele, cultura da mídia, a caracterização dessa cultura e o contexto em que são realizadas suas pesquisas. Ao longo do livro, ele observa como as produções culturais veiculadas pela mídia influenciam comportamentos e constroem identidades no mundo pós-moderno, estabelecendo uma nova relação da cultura com a vida social. Enquanto que antes dos anos 80 havia uma proeminência das relações políticas na organização da vida social, no pós-anos 80 haverá uma explosão da cultura em toda esfera da vida social.

Baseando-se na questão da conformação dos padrões sociais, Kellner define o que é cultura da mídia. Ele reflete sobre essa questão considerando o momento em que a indústria cultural foi potencializada pelo processo de globalização do desenvolvimento tecnocientífico, sendo um dos principais investimentos da $3^{\text {a }}$ revolução industrial, ou revolução tecnocientífica, na área da comunicação (robótica, informática, biotecnologia e as tecnologias de informação).

Segundo Kellner, essa cultura do pós-anos 80 é produzida com uma intenção, ou seja, ela não é o espaço para a neutralidade. A cultura da mídia, a qual ele chama de tecnocultura, é uma cultura voltada para o mercado e produzida industrialmente, ou seja, ela passa por uma padronização e por uma produção em série. Dessa forma, Kelnner diz que a mídia não é só um reflexo da sociedade, mas também uma das construtoras desses paradigmas sociais, isto é, a mídia forma e é formada por essa sociedade. A mídia não só se apropria do que já está construído socialmente, mas principalmente, no pós-anos 80 , ela será o principal veículo de construção, por conta da globalização e do desenvolvimento tecnológico.

Através das práticas de significação construídas pelas mídias, se formarão modelos de comportamento a serem reproduzidos, modelos estes de uma classe dominante com grande poder econômico e/ou político que consegue a hegemonia, isto é, consegue o convencimento de todo o conjunto da sociedade de que aquele é o melhor modelo a ser seguido. Essa hegemonia se conquista via instituições da cultura, ou seja,

\footnotetext{
${ }^{1}$ Aluno do curso de graduação de Comunicação Social da PUC-Rio, 2016.1

2 KELLNER, Douglas. Cultura de mídia. Estudos culturais: identidade política entre o moderno e o pós-moderno. Bauru: EDUSC, 2001.
} 
via educação, via meios de comunicação. A isso o filósofo italiano Antonio Gramsci ${ }^{3}$ (1926), em seu livro Cadernos do Cárcere, vai chamar de consenso, isto é, um processo de convencimento, consenso de toda sociedade ou de boa parte dela em torno do projeto social de uma classe. Tais modelos são projetados por meio de interesses, tanto individuais quanto coletivos, em complexos processos de significação que definem a construção histórico-social das classes de uma sociedade, de acordo com o contexto em que se está inserido.

Essas práticas de significação podem ser observadas nos filmes de animação voltados ao público infantil, os quais, em sua grande maioria, apresentam em suas narrativas as diferenças de gênero de forma convencional e conservadora: homens são fortes, racionais, heróis, poderosos. Já as mulheres, mesmo as heroínas, se apresentam de maneira submissa aos homens e são frágeis, desprovidas de poder e sensuais. Filmes como Branca de Neve e os Sete Anões (1937), Cinderela (1950) e A Pequena Sereia (1989) são exemplos de reprodução desse modelo tradicional. Contudo, em outras produções, pode-se observar que as regras sociais e as atitudes convencionais são sutilmente reformuladas. Filmes como Pocahontas (1995), Mulan (1998) e os mais recentes do século XXI, como A Princesa e o Sapo (2009), Valente (2012), Frozen (2013), Zootopia (2016) e Moana (com previsão de lançamento para final de 2016, nos EUA, e para início de 2017, no Brasil) podem ser citados como exemplos dessa diferente forma de expressão que direciona para uma redefinição do gênero feminino nas produções para o público infantil.

Tais filmes são retratos fieis dessa mudança de visão da mulher e de seu papel no mundo. A par de trazerem histórias de princesas, não as mostram como frágeis a serem salvas por um príncipe encantado, mas sim como mulheres que quebraram regras e lutaram em prol de seus sonhos e desejos. Nem todas "viveram felizes para sempre" casadas com um príncipe, mas revelaram sua própria integralidade enquanto mulher. Mulan é uma dessas personagens que celebra a honra, a coragem e o esforço de uma mulher em busca da aceitação de uma sociedade conservadora e tradicional. A história tem como cenário a China Imperial, sociedade em que mulheres só eram vistas como esposas e mães, não podiam falar em público, nem mesmo se dirigir a um homem. Dessa forma, o que se observa na grande maioria das personagens do filme é a rotulação das identidades de gênero, reforçando os estereótipos e a manutenção de um conservadorismo heterossexual, ou seja, há um predomínio materializado daquilo que

\footnotetext{
${ }^{3}$ GRAMSCI, Antonio. Cadernos do cárcere. Disponível em https://umhistoriador.wordpress.com/2012/05/20/cadernos-do-carcere-de-antonio-gramsci-disponivelonline/, acesso em 01 dez. 2016.
} 
se considera socialmente ser homem e ser mulher, um modo de ser masculino e um feminino. A personagem que irá romper, de certa forma, com esses padrões será Mulan.

No filme, a protagonista é considerada despreparada para o casamento após uma espécie de "teste de casamenteira" por não ter os atributos, que, segundo a cultura de seu povo, a levariam a ser uma boa esposa e mãe: educada, comportada, discreta. Isso é demonstrado por Gramsci como coerção. Segundo o filósofo, toda estrutura social, para se sustentar, se baseia em dois pilares: a coerção e o consenso. A coerção é toda a parte em que se seguem determinadas convenções sociais, porque estas são impostas a serem seguidas. Se não forem cumpridas haverá repressão física e/ou moral. Em uma sociedade mais próxima de uma ditadura há mais necessidade de coerção, ou seja, controle da produção de cultura, censura, repressão e tortura.

Em Mulan, rompe-se com o paradigma social convencional: é a mulher quem é forte e protetora. É ela quem salva o país a partir de decisões racionais elaboradas estrategicamente. É pela bravura que a mulher concretiza sua emancipação em contextos sociais, culturais, políticos e históricos, mudando-se os estereótipos de princesa, na tentativa de igualdade das identidades de gênero. Mulan é uma crítica profunda ao sistema excludente e conservador da China do século $V$, em que se veem resquícios desses pensamentos e comportamentos histórico-sociais nos dias atuais.

Vê-se o cinema como um importante mecanismo em que se permite promover discussões em torno de gêneros, sexualidades e subjetividades. Em Mulan é admitida uma dúbia leitura: de um lado, a afirmação constante das qualidades de que se deve ter uma mulher e, de outro, a representação do homem como ser abjeto. Tem-se, portanto, a evocação da identidade de gênero como reiteração e subversão ao mesmo tempo. Reiteração quando aparecem valorizadas as qualidades femininas como sendo destinadas ao matrimônio e à maternidade e subversão quando é dada oportunidade a uma personagem feminina de se destacar a partir da identidade masculina.

Tendo isso em vista, a The Walt Disney Company, um dos maiores conglomerados de mídia e entretenimento do planeta, instaurou e consolidou uma indústria de animação a qual dissemina os valores da empresa em seus enredos, compondo e transformando os processos subjetivos dos espectadores através de sua forte influência midiática. Contudo, segundo sugere Márgara Averbach ${ }^{4}$, Doutora em Letras e Tradutora Literária argentina:

(...) é importante mencionar que os valores que se apresentam nos filmes da Disney vão mudando conforme a evolução das novas sociedades. Isto se pode observar de forma clara desde o filme de Branca de Neve, onde a mulher representava o papel típico de dona

4 AVERBACH, Márgara. Huellasimperiales. Buenos Aires: Imago Mundi, 2003, p 163-175. 
de casa. Por outro lado, com as novas produções, se pode observar uma evolução dentro dos filmes, onde as protagonistas como Bela, Mulan, Ariel, Jasmine, desempenham papéis distintos, desafiando a sociedade tradicional. ${ }^{5}$

Segundo a autora, essa mudança é decorrente da polissemia feminina, isto é, dos diversos papéis que a mulher desempenha na sociedade atual.

A questão central no filme gera um debate em torno da temática de gênero. $O$ papel da mulher na sociedade patriarcal chinesa da época e o contexto social que se vive a partir do filme contribuem para o questionamento sobre a sociedade atual, o que possibilita a discussão da questão de gênero, de identidade e de ideologias machistas e feministas.

É possível compreender que, mesmo progredindo sensivelmente os questionamentos através da representação de princesas em filmes voltados para o público infantil, é inquestionável o fato de que a Disney é uma empresa que tem interesses comerciais. Mesmo as personagens com maior "empoderamento" são fruto de uma demanda social, em que cada princesa reflete a ideologia da época em que foi criada. As mulheres mudam e, juntamente com elas, a indústria cinematográfica se adequa, a fim de transmitir maior grau de realismo para com seu público.

Mulan representou a primeira chama de que o cinema de animação enquanto veículo de comunicação crítico feito, primariamente, para o público infantil precisava apresentar as reais representações da mulher. Não existe um único padrão de princesa, assim como não existe um único padrão de ser mulher. Como diz a personagem Merida no filme Valente: "nosso destino vive dentro de nós".

\section{Referências Bibliográficas:}

AVERBACH, Márgara. Huellasimperiales. Buenos Aires: Imago Mundi, 2003.

GRAMSCI, Antonio. Cadernos do cárcere. Disponível em https://umhistoriador.wordpress.com/2012/05/20/cadernos-do-carcere-de-antoniogramsci-disponivel-online/, acesso em 01 dez. 2016.

KELLNER, Douglas. Cultura de mídia. Estudos culturais: identidade política entre o moderno e o pós -moderno. Bauru, SP: EDUSC, 2001 